\title{
Patriotismo e responsabilidade na época da globalização
}

Alessandro Pinzani ${ }^{I}$

\section{Introdução}

Ao falar de ética na política, o pensamento vai de maneira quase inevitável à questão da corrupção dos políticos e dos membros do governo: neste sentido, o Brasil e o meu país, a Itália, são parecidos. Isso lembra-me uma piada muito popular na Itália. As Nações Unidas enviam aos estados membros a seguinte questão: "Que opinião tem honestamente do fato de que no mundo tantos países sofrem devido à escassez de alimentos?" Os países europeus respondem que não entendem o sentido da palavra "escassez". Os países africanos, que não entendem a palavra "alimentos". Os chineses respondem que não sabem o que significa "opinião". Os Estados Unidos têm problema em entender o sentido da palavra "mundo". No parlamento italiano ainda se quebram a cabeça para entender o que significa "honestamente".

Ao falar de ética em relação à globalização, porém, vem à mente a questão da ética das empresas, particularmente em relação às questões do meio ambiente, dos direitos dos trabalhadores, das responsabilidades das empresas perante a sociedade etc.

${ }^{1}$ Doutor em filosofia pela Universidade de Tübingen, onde atua como pesquisador; atualmente é professor visitante na Columbia University, em Nova Iorque. Texto apresentado no Observatório Social da Pucrs, durante o Fórum Social Mundial de 2002, em Porto Alegre.

Endereço: apinzani@aol.com 
Ainda que tratem-se de dois temas muito importantes, cruciais até, não somente da teoria política, mas também da vida política mesma, hoje gostaria de apontar um outro aspecto pelo qual pode-se falar dum cruzamento de temas éticos e políticos com respeito ao fenômeno da globalização. Refiro-me à questão do que significa ser um cidadão na época da globalização.

A reflexão sobre o papel do cidadão tem uma longa tradição a partir da antigüidade. Sócrates, Platão, Aristóteles ocuparam-se deste tema, que permanece, ainda de maneira mais ou menos evidente, um dos mais centrais na história do pensamento político até o presente. Também Rawls, Dworkin, Habermas ocuparam-se dele, e em anos recentes a questão das virtudes cívicas voltou a dominar a cena dos debates acadêmicos, particularmente no mundo anglo-saxão, como demonstrado por inumeráveis publicações científicas (citarei aqui somente os nomes de Galston, Macedo e Dagger).

Mas neste fluxo de interesse pelo papel do cidadão na vida política do estado, só alguns autores relacionaram este tema à questão da globalização, e a maioria deles foram sociólogos. Por outro lado, os poucos filósofos que ocuparam-se do tema têm grandes nomes: Jürgen Habermas, Otfried Höffe, Will Kymlicka. O tema fica, porém, bastante inexplorado para justificar investigações posteriores. Esta palestra queria ser precisamente uma tentativa de investigar dois aspectos fundamentais conexos ao papel do cidadão: primeiramente o patriotismo e secundariamente a consciência da própria responsabilidade que se presume que os membros duma comunidade política tenham que mostrar reciprocamente.

A causa principal da relativa falta de clareza que ainda domina em relação à questão do papel do cidadão na época da globalização pode ser individualizada na dificuldade de definir os próprios conceitos fundamentais necessários para ocupar-se do tema mesmo. O conceito mais renitente neste sentido é obviamente o próprio conceito de globalização. Portanto, precisará duma pequena tentativa duma definição mínima da globalização. Ao fazer isso já se delinearão temas conexos à questão da cidadania.

Mas antes de falar disso, queria apontar outro aspecto. Muitas vezes, ao falar de ética e globalização, há quem se refira a questões de justiça social, como a pobreza em muitos países, a desigualdade econômica entre países industrializados e países não industrializados etc. Ainda que essas questões tenham importantes conseqüências morais, pois elas atingem a vida, a saúde e a liberdade de 
seres humanos, não é fácil denominar questões de justiça social como questões éticas. Numa visão tradicional, questões de justiça são questões relativas ao que é devido, independente de quem seja o ator das ações em questão - se indivíduo ou instituição - e de que os objetos destas questões sejam a conduta dum indivíduo, o caráter duma pessoa ou regras sociais. Neste sentido fala-se, por exemplo, dum comportamento justo, duma pessoa justa ou duma lei justa. Numa visão mais moderna, típica de muitas teorias da justiça contemporâneas, como aquela de Rawls, as questões de justiça só dizem respeito às regras sociais ou às instituições, enquanto a conduta e o caráter são reconduzidos a uma dimensão de moralidade individual, no reino da própria ética. No máximo pode-se falar de justiça com respeito ao comportamento do indivíduo como cidadão: enquanto ela contribua para estabelecer e reforçar instituições justas, uma pessoa é justa. As únicas virtudes da quais fala Rawls são as virtudes do cidadão, ou seja, as virtudes necessárias para o estabelecimento e a manutenção duma sociedade justa. Não é por acaso que a maioria das teorias da justiça social que têm como objeto o estabelecimento duma sociedade global justa falam mais nas instituições internacionais que nas linhas de conduta individuais. Pratica-se muita engenharia institucional neste sentido, mas fala-se pouco da ética dos indivíduos na era da globalização, apesar dos filósofos já mencionados.

Não tenho a intenção de tomar uma posição sobre qual destas visões seja correta. Concederei em considerar como válida a segunda perspectiva, a mais moderna, e tentarei demonstrar como mesmo a partir dessa perspectiva seja necessário que os indivíduos enquanto cidadãos promovam a justiça social, embora ela seja um atributo de entidades como as regras sociais ou as instituições.

\section{O que é a globalização?}

Para alcançar uma definição mínima da globalização, apontarei alguns aspectos sobre o quais concorda a maioria das teorias da globalização.

O primeiro aspecto é que a globalização, embora não constitua uma ruptura com a tradição da modernidade, marca o abandono do paradigma central desta, ou seja, o paradigma do progresso como fenômeno ligado à temporalidade. Enquanto a modernidade tinha feito do tempo o teatro da transformação econômica, política, social e moral da humanidade: isso é, do progresso, a globalização anula por assim dizer a temporalidade, reduzindo-o ao breve momento, ao ins- 
tante necessário para a transferência de informações dum ponto ao outro do planeta através dos "novos" meios tecnológicos: o telefone, o rádio, a televisão, o computador. As grandes transformações sobressaltam a humanidade de repente e tomam posse do mundo num tempo incrivelmente breve para os nossos antepassados: elas se movem mais na dimensão espacial que na temporal. $\mathrm{O}$ espaço constitui o eixo sobre o qual procede o fenômeno da globalização, enquanto o tempo era o eixo sobre o qual avançava o progresso exaltado pela modernidade. Mas, enquanto que o progresso, por causa da sua própria natureza temporal, era algo previsível ou pelo menos que se podia observar, um fenômeno que podia ser seguido e registrado, ao menos na opinião dos seus teóricos, isso não é possível no caso da globalização.

Obviamente estou exagerando. O progresso ainda não era de modo algum linear, previsível e registrável como afirmavam o seus teóricos. Porém, o que conta é o fato que as ideologias que o acompanhavam, seja aquelas que aclamavam-no com entusiasmo, seja aquelas mais críticas, concebiam-no assim. Pelo contrário, ninguém tem uma visão assim clara e nítida da globalização, apesar de Fukuyama e de alguns terríveis simplificadores. A globalização dificulta ainda a construção de teorias sobre ela. Por isso nasceram tantas teorias tão diversas.

Em todo o caso, fica acertado que a globalização fez "saltar" o espaço tal qual a modernidade o concebia - não me refiro obviamente ao espaço da física, senão àquele da economia e da política. Com a globalização aconteceu uma modificação profunda neste sentido. Com a "explosão" do espaço vieram ao primeiro plano aqueles sujeitos econômicos e políticos menos ligados ao espaço mesmo: não somente as multinacionais, ou mais precisamente: as companhias transnacionais; mas sim ainda sujeitos que na sua ação servem-se das novas tecnologias, desembaraçando-se por assim dizer do espaço: especuladores financeiros, mas também os assim chamados sujeitos antagônicos - dos hackers até as organizações não governamentais internacionais, as redes neonazistas, os simples navegadores da Internet. As novas tecnologias permitem uma ubiqüidade virtual na qual é possível ser sujeito em situações remotas, influenciando-as ainda de maneira decisiva, como no caso mencionado dos especuladores financeiros. Também isto não é uma novidade absoluta. Por exemplo, ainda na idade média as decisões tomadas pelos banqueiros florentinos influenciavam a política do rei da Inglaterra, que dependia dos seus empréstimos. Mas nestes casos haia um hiato temporal entre um acontecimento, uma ação ou uma decisão e as suas 
conseqüências. Hoje em dia, as coisas não estão mais assim. A decisão dum banco sobre a aprovação de créditos para um governo estrangeiro pode ter conseqüências imediatas e dramáticas, como demonstram os exemplos recentes da Argentina ou de outros países, da Indonésia ao México.

Numa tal situação, as maiores dificuldades surgem evidentemente para os sujeitos econômicos e políticos mais ligados ao território. O caso mais grave é aquele do estado, que por definição se identifica com um determinado território, além do qual a sua influência e a sua capacidade de ação são na maioria dos casos muito limitadas, apesar da exceção de alguns países como os Estados Unidos ou a China - estes porém só em virtude dos seus armamentos ou duma política de ingerência forte e muitas vezes ilegal nas questões internas de outros países; eles tornaram-se sujeitos transnacionais como os grande grupos econômicos (mencione-se só as numerosas "filiais" que o Pentágono abriu no mundo, mesmo em Cuba, com a base de Guantânamo).

Chegamos assim ao segundo aspecto sobre o qual todas as teorias da globalização concordam: o predomínio da lógica econômica. Sem dúvida a globalização não é um fenômeno limitado à economia e à expansão do mercado. Ao contrário, analisando bem a questão, percebe-se que esta expansão é limitada aos países industrialmente mais avançados, e a vasta maioria das transações comerciais acontecem ainda no âmbito da triângulo Estados Unidos - Europa - Japão, enquanto para os outros países, particularmente os africanos, só ficam as migalhas. ${ }^{2}$ E sem dúvida tem uma globalização que vai além das simples transações comerciais ou das especulações financeiras. Refiro-me às tendências das várias culturas para abrirem-se à influência de outros âmbitos culturais que até há pouco ficavam praticamente desconhecidos. E não tem importância se a assim chamada globalização cultural possui uma notável dimensão econômica ligada à comercialização da própria cultura, da arte, da música e da literatura. Se Cesária Evora conquista as paradas de sucesso estadunidenses, isso acontece mais pela ação das multinacionais do disco que por um interesse verdadeiro dos cidadãos estadunidenses pela música e a cultura de Cabo Verde. Porém, qualquer que seja a causa deste fenômeno, na vida cotidiana intensifica-se o contato com culturas diversas da sua própria e aumenta a curiosidade por outros estilos de vida e por outras visões do mundo. Para alguns trata-se duma curiosidade consumista, liga-

${ }^{2}$ Queria que as numerosas vozes críticas que se levantam na América Latina para denunciar justamente as injustiças e as prepotências dos países do Norte não suscitassem a impressão de que este continente detém o monopólio do sofrimento, mas lembrassem também da África. 
da à busca de novos produtos que satisfaçam as próprias exigências de variedade, e portanto trata-se dum contato superficial limitado ao tempo livre, como por exemplo ao jantar num assim chamado restaurante étnico. Para outros, pelo contrário, trata-se de ultrapassar os limites do seu Lebenswelt, do seu mundo da vida, e de relativizar as próprias convicções. Qual dentre as duas atitudes resultará decisiva no final, isso não podemos saber. Também a este respeito a globalização permanece um fenômeno imprevisível com êxitos não prognosticáveis.

Porém, a despeito dessa globalização cultural, se assim quisermos chamá-la, segue inegável que o aspecto econômico seja o predominante, e não somente por causa da expansão do comércio mundial, mas pela prevalência quase incontestada da lógica tipicamente econômica do lucro. Uma lógica que se insinuou ainda no mundo da política, substituindo qualquer ideal social diverso daquele neoliberal do mercado sem limites. Hoje em dia vencem as eleições não os políticos que saibam oferecer ao povo a visão mais atrativa do que para ele a sociedade deveria vir a ser, mas sim aqueles que prometem ser administradores zelosos que saibam obter de modo mais rápido os créditos necessários das organizações internacionais como o Banco Mundial, ou os que prometem induzir empresas estrangeiras a investir no país, ou que prometem cortar as "inevitáveis" despesas sociais no modo mais eficaz ou mais indolor possível. A diferença entre direita e esquerda se limita hoje quase sempre à escolha entre eficácia e prudência nos cortes, cuja legitimidade ninguém põe em questão.

Estou exagerando outra vez. Paradoxalmente isto acontece sobretudo nos países mais industrializados, ou seja, nos países que poderiam permitir-se ter grandes visões. Precisamente nos países mais dependentes da benevolência do Banco Mundial ou do Fundo Monetário Internacional levantam-se as vozes mais críticas contra esta mentalidade. Mas ao final também nestes países os governantes devem dobrar-se à lógica férrea da estabilidade econômica, da diminuição da dívida pública, da desregulação, da privatização etc. Quão penetrante é esta lógica é demonstrado também pelo fato de que ela se insinuou ainda em instituições que por sua natureza não foram criadas para o lucro, como museus e universidades. Nos países industrializados, que tanto gostam de autodenominarem-se "avançados", os maiores financiamentos vão somente àquelas faculdades ou àqueles projetos que prometem resultados econômicos para as universidades através de patentes ou patrocinadores privados, com muitas saudações à liberdade acadêmica. 
Esta prevalência da mentalidade econômica foi interpretada por alguns pensadores como a causa principal dos problemas ideológicos criados pela globalização, problemas cuja expressão mais aguda e violenta seriam as várias formas de fundamentalismo: étnico, nacionalista ou religioso. Marx - aquele Marx que, segundo uma leitura prevalente nos anos noventa, teria errado em tudo - Marx já no Manifesto falou neste tema, na homogeneização cultural resultante da criação dum único mercado mundial e nas conseqüentes resistências das culturas particulares. Benjamin Barber (1995) sintetizou este processo na célebre fórmula "Jihad contra McWorld", embora ele sublinhe que o fundamentalismo ao qual se refere não seja só aquele islâmico e de que a globalização econômica na qual ele fala não seja só aquela que nos permite de encontrar um McDonald's praticamente em cada lugar do mundo. Em todo o caso, este dualismo pareceria ter alcançado o seu ápice no dia 11 de setembro de 2001, no qual a Jihad (neste caso justamente a islâmica) golpeou no coração o símbolo mais triunfal do McWorld.

Esta versão parece plausível, mas eu desconfio de interpretações redutíveis a uma fórmula ou de teorias que reduzam fenômenos tão complexos a uma única causa. Não existem explicações monocausais nem da globalização econômica, com a sua prevalência da mentalidade econômica, nem do fundamentalismo, com as suas guerras com fundo étnico como em Ruanda ou na Iugoslávia, e com as suas formas terroristas, da ETA até Al Qaeda. Numa palavra: não creio nas filosofias da história que tentam ler um único sentido em eventos tão distantes no espaço e acontecidos em contextos tão diversos como justamente as guerras étnicas de Ruanda e da Bósnia.

A crescente influência da mentalidade econômica não possui a necessidade dum evento natural, mas é fruto de determinadas decisões políticas que levaram a uma momentânea prevalência da economia sobre a política. Porém, não há razão para pensar que este predomínio seja definitivo, nem para pensar que o único modo para opor-se a ele seja entrincheirar-se numa recusa total de qualquer forma de conexão internacional, numa recusa da globalização em geral. Afinal, para utilizar a fórmula de Barber, não existem só a Jihad ou o McWorld. Necessita-se encontrar alternativas a estas duas posições extremas, e acho que eventos como este Fórum sejam muito importantes neste sentido, pois são a expressão duma crescente consciência do fato de que se pode e se deve fazer algo para criar um mundo mais justo.

Neste contexto, em que sentido se pode falar duma ética da cidadania? 


\section{O cidadão, a nação, a pátria}

Se uma das características mais salientes da globalização consiste na redução do papel do estado, o papel dos cidadãos poderia resultar comprometido, pois o próprio conceito de cidadão só pode ser definido com respeito à idéia de estado. Sem estado não há cidadãos, mas sim simples indivíduos. Isto remetenos a um ponto muito importante: o status do cidadão é in primis um status jurídico e não tem a ver com a natureza do indivíduo ou com a sua identidade cultural.

$\mathrm{Na}$ realidade, esta visão formal da cidadania vem sendo posta em questão por todos que consideram a pertinência a uma comunidade política como uma coisa que plasme profundamente a identidade pessoal do indivíduo. Neste caso também temos de lidar com um amplo espectro de teorias: daquelas mais extremas, que identificam a comunidade política com um grupo étnico, até aquelas mais moderadas, que apontam o aspecto emocional da relação entre cidadão e estado, aspecto indicado normalmente com o conceito de patriotismo ou de amor pela pátria. As duas famílias teóricas que nos anos mais recentes defenderam mais energicamente a idéia de que a comunidade seja prioritária perante o indivíduo, seja cronológica seja normativamente, são sem dúvida o comunitarismo e o republicanismo, ou mais corretamente: o neo-republicanismo, pois este movimento relaciona-se com uma tradição que remonta ao menos à época romana.

Muitas destas teorias são na verdade teorias normativas mais que simples descrições ou que simples definições do que seja um cidadão. Acho que seja importante refutá-las ou ao menos oferecer uma abordagem alternativa, pois só neste momento seria possível propor uma teoria da cidadania capaz de dar um sentido à personagem do cidadão também na era da globalização. Antecipo que se tratará duma teoria por sua vez normativa nos êxitos, ainda que ela se baseie em considerações de caráter empírico-descritivo com respeito à formação duma comunidade política.

Portanto, começarei justamente por este conceito. Uma comunidade política é sempre uma comunidade aberta: primeiro temporalmente, perante o futuro, mas também espacialmente, perante as outras comunidades ou os indivíduos alheios a ela, os assim chamados estrangeiros - palavra que utilizo no sentido neutro e jurídico de "não-cidadãos". Precisamente este ponto é o menos apontado ou até o mais contestado na história do pensamento político. Geralmente a 
comunidade política é considerada como uma entidade fechada em si, à qual vem atribuída uma identidade pessoal em analogia com o indivíduo. Esta mesma analogia constitui o obstáculo maior para uma correta compreensão das questões das quais estamos falando.

No momento em que vem a ser atribuída uma identidade pessoal à comunidade política (freqüentemente até com caráter e qualidades específicas que desembocam em estereótipos como: a anarquia dos italianos ou dos brasileiros, o amor à ordem dos alemães etc.), neste momento são atribuídas a ela também as mesmas necessidades ou até os mesmos direitos dos indivíduos, começando pelo direito à sobrevivência ou à liberdade de ação. Alguns pensadores, como Otfried Höffe, falam mesmo de "direitos humanos para os estados" (1999: 324). Em casos extremos, houve quem atribuiu-lhes um "sacro egoísmo", ou conferiu-lhes "missões históricas", ou falou de "espaços vitais" necessários à sobrevivência.

Esta analogia entre estados e indivíduos se baseia num mal-entendido básico, pois ela concebe a identidade coletiva como a identidade dum ator singular, precisamente o coletivo, enquanto na realidade a identidade coletiva é o fruto das idéias que um certo número de indivíduos possuem de si mesmos como membros daquela comunidade. Só no momento em que estas idéias coincidem de maneira relevante, nasce uma identidade coletiva - ou melhor: "de grupo", como sublinha com razão Furio Cerutti (1996: 6). Uma tal identidade consiste portanto "no conjunto daqueles elementos das identidades individuais que concernem à definição do grupo mesmo e que são compartilhados por vários indivíduos, contanto que os segmentos de identidade individual não compartilhados não sejam tais - por alcance e importância - que fique impossível um consistente idem sentire (sentimento comum) entre os membros do grupo" (ibid.: 6). Sem este sentimento comum obviamente o grupo cessaria de existir. Isso não significa insistir num presumido aspecto volitivo da formação das comunidades políticas, como se o contrato social das teorias contratualistas modernas fosse uma realidade histórica e não uma simples ficção no âmbito duma teoria da legitimação do poder político. Isso significa, ao contrário, apontar para a dimensão histórica na qual uma certa comunidade se constitui através do nascimento duma identidade de grupo entre indivíduos que até então não se consideravam membros dela. E significa também relevar que esta identificação, além de não ser dada historicamente de uma vez por todas, não é nem imutável (diacronicamente), nem rigidamente definida (sincronicamente). Em outras palavras: é possível que os elementos compartilhados pelas concepções individuais, elementos que formam a identidade dum grupo, mudem no tempo, le- 
vando eventualmente à crise dessa identidade. Tome-se por exemplo a Bélgica, que nasceu da identificação comum dos flamengos e dos valões na tradição católica compartilhada, e que hoje é ameaçada na sua unidade política porque os dois grupos (particularmente os flamengos) insistem nas diferentes culturas lingüísticas. Igualmente é possível que os indivíduos que formam uma comunidade tenham concepções extremamente diversas sobre ela, mas com elementos comuns suficientes para dar vida a uma identidade de grupo.

Isso significa também que a composição da comunidade mesma pode mudar através da inclusão (ou exclusão) de indivíduos até então excluídos (ou incluídos); e que, portanto, os membros duma comunidade podem dar vida em tempos diversos a diversas identidades de grupo. As dificuldades conexas a tais processos não são ligadas ao fato presumido de serem diferentes comunidades irredutíveis uma com a outra: a história mostra-nos o contrário, e em todo o caso as comunidades podem fundir-se materialmente umas com outras, ao contrário dos indivíduos (os limites geopolíticos são imateriais, ao contrário dos limites do corpo humano - banalidade que alguns pensadores esquecem demasiadas vezes). As dificuldades surgem, antes, da incapacidade ou da falta de disposição, por parte dos indivíduos, para mudar as próprias concepções do grupo e adaptálas a uma nova realidade política.

Isso implica numa redefinição do próprio conceito de comunidade política e de nação. Em vez de remeter para elementos substanciais como um território, um idioma ou uma história comuns, ${ }^{3}$ ressaltam aqueles aspectos do processo de criação duma identidade de grupo que muitas vezes são menosprezados ou deixados de lado, como a dimensão relacional (cf. Young 1998). Para nascer, uma comunidade quase sempre precisa de outra a qual contrapor-se. Digo isso não no sentido da luta hegeliana pelo reconhecimento, mas naquele mais banal de que é mais fácil definir-se a si mesmo através da confrontação com os outros: "Nós não somos eles", "Nós somos diversos deles" ou, simplesmente, "Nós não queremos ser eles, embora sejamos similares ou até iguais" (nem todo separatismo ou particularismo baseia-se em diferenças substanciais, ou seja, em diferenças culturais, lingüísticas, religiosas etc.). Às vezes há comunidades que parecem ter a necessidade de seguir definindo-se primariamente com respeito ao exterior, freqüentemente com respeito a um inimigo. Acho que o exemplo melhor (e mais trágico) desta atitude seja oferecido neste momento por israelitas e palestinos (cf. Kelman 1987; Pinzani 2002). Deveríamos perguntar-nos quão estável internamente seriam as sociedades israeli-

\footnotetext{
${ }^{3}$ Isto acontece ainda em W. Kymlicka (1995).
} 
ta e palestina caso alcançassem uma situação de paz definitiva. Não causa surpresa o fato de que devemos registar uma persistente falta de boa vontade de uma parte e de outra para resolver definitivamente o conflito, pois em jogo está a própria identidade dos dois grupos, não somente o território e a autonomia política; por conseguinte, a solução melhor (utópica como todas as soluções melhores) consistiria justamente na renúncia à própria identidade de grupo atual, para aceitar uma nova identidade na qual o outro é incluído ao menos como vizinho (e não como potencial inimigo) ou até como concidadão.

Deixada para trás esta fase, os membros duma comunidade começam a identificar-se como tais já não na base dum elemento externo, duma outra comunidade, mas sim na base de critérios internos (usualmente os mencionados elementos substanciais como história, idioma, cultura, religião etc., mas ainda instituições comuns, como veremos). Por fim, como dizem os bávaros: "Mir san mir", nós somos nós. A lógica da contraposição entre "nós" e "eles", típica do nacionalismo ou de certas concepções do patriotismo, é a lógica duma comunidade débil no fundo, incapaz de definir-se de modo diferente da contraposição negativa a um rival ou até a um inimigo externo. Neste sentido Barber, e Marx antes dele, tem razão em dizer que os nacionalismos com base étnica combatem uma batalha de retaguarda. O nacionalismo é sinal de fraqueza.

\section{Verfassungspatriotismus e patriotismo da responsabilidade}

Quando as comunidades políticas dão vida a um estado, o quadro já bastantemente complexo enriquece por um novo elemento: o ordenamento constitucional - seja ele fixado numa carta constitucional, seja ele simplesmente transmitido historicamente. Entre todos os aspectos que podem levar a atribuir uma identidade pessoal a uma comunidade política, este é um dos mais vigorosos. Contrariamente a outros elementos como idioma, cultura, território etc., que freqüentemente são porosos e variáveis, uma constituição representa algo de sólido, em redor do qual a comunidade vem a organizar-se de maneira relativamente compacta como entidade estatal. Não devemos porém atribuir demasiado valor à continuidade garantida por uma constituição. Ao contrário, a constituição testemunha que uma comunidade política, longe de ser uma entidade natural, é o fruto da reunião do seus membros. Isso manifesta-se entre outras coisas no caráter convencional que a constituição compartilha com todas as outras normas jurídicas. (Não esqueçamos que a constituição é só um conjunto de normas, embora 
de tipo particular.) A constituição, portanto, pode ser considerada como a expressão da vontade dos membros duma comunidade em dar vida a uma entidade estatal. Mas ela não é algo eterno nem imutável. Os membros podem mudar de idéia, resolver modificá-la ou até aboli-la. Por fim, eles podem decidir dissolver a sua comunidade para dar vida a uma nova e mais ampla comunidade (assim nasceu, por exemplo, o Reino de Itália, em 1861) ou a comunidades mais pequenas (como no caso da dissolução da Checoslováquia).

Ao mesmo tempo, a constituição oferece aos cidadãos a possibilidade duma identificação mais forte com a comunidade política do que elementos como o idioma ou a cultura (para não mencionar a etnia) ou até a história comuns. Os eventos históricos são ambíguos e só raramente permitem uma interpretação univocamente positiva, a não ser que se criem mitos como no caso de Guilherme Tell na Suíça ou da conquista do Oeste dos Estados Unidos, que por tantos anos foi mitificada como momento constitutivo da nação e recentemente foi justamente reinterpretada também como genocídio contra os povos indígenas. A questão é que quase nunca os heróis se prestam para exaltações incondicionais. O patriotismo não é uma religião, também não uma religião laica e civil; ele não precisa de santos, mas no máximo de bons exemplos.

A constituição não é, portanto, uma Escritura Sagrada, embora possa representar uma tradição à qual se pode apelar. Os seus princípios e as suas normas estabelecem uma continuidade com o passado, com as gerações precedentes dos membros da comunidade política, possibilitando aos membros atuais sentiremse parte integrante duma tradição, sem portanto ser seus escravos. A já mencionada circunstâncias de que a constituição possa ser modificada - embora esta modificação seja usualmente vinculada rigorosamente a critérios muito exigentes -, revela a dimensão de abertura perante o presente e o futuro da comunidade política cuja vida ela regula juridicamente (cf. Fioravanti 1993; Frankenberg 1997). Portanto, ainda que fiquem dentro da tradição encarnada na constituição, os cidadãos podem dar uma nova interpretação à comunidade política, modificando a constituição mesma. A última oferece aos membros duma comunidade política a moldura dentro da qual eles podem dar vida àquela forma de vida comum que creiam a mais oportuna - moldura que eles podem justamente modificar no momento em que julguem que ela já não responda ao projeto comum deles. 
Nesta ótica, alguns pensadores, especialmente Sternberger (1990) e Habermas (1996), são da opinião de que as instituições dum estado possam oferecer aos cidadãos um elemento comum sobre o qual basear a própria lealdade patriótica. Eles querem substituir a pátria entendida como Vaterland, ou seja, como entidade nacional e cultural, por uma pátria como Verfassung, como constituição, como projeto comum. Este Verfassungspatriotismus - patriotismo constitucional - possibilitaria o desenvolvimento dum idem sentire, dum sentimento comum independente das diversas filiações culturais ou religiosas, e até das diversas proveniências nacionais - como (teoricamente!) nos Estados Unidos, onde todos podem, se quiserem, seguir considerando-se como pertencentes aos diversos grupos nacionais de proveniência (pessoal ou dos seus antepassados), mas ao mesmo tempo devem identificar-se primeiro como cidadãos estadunidenses, em perfeita igualdade e no pleno respeito das instituições comuns.

Eis-nos no ponto onde a ética individual e a questão da justiça social das instituições ou das regras sociais se cruzam. Geralmente o patriotismo constitucional justifica a simpatia ou a identificação com uma determinada constituição na base do suposto de que ela seja uma constituição justa, ou seja, uma constituição que garante iguais liberdades aos cidadãos, que permite-lhes uma participação ativa na vida pública, que assegura-lhes direitos sociais fundamentais etc. ${ }^{4}$

Há quem ataque o patriotismo constitucional precisamente porque este proclamaria "a lealdade a princípios políticos universalistas, cultural e historicamente neutros" (Viroli), como a própria justiça das instituições. Ao responder a esta crítica é preciso relevar primeiramente que a justiça é de fato um critério universalista, cultural e historicamente neutro, mas na medida que outros critérios como a liberdade ou a independência do arbítrio alheio (o critério máximo dos republicanos) também o são. Além disso, o patriotismo constitucional não é cego perante a circunstância de serem as instituições em questão as instituições concretas duma certa comunidade - instituições e comunidade que são ambas determinadas historicamente. Ao mesmo tempo, porém, ele não requer que os cidadãos "amem" aquelas instituições simplesmente porque são as deles, mas exige uma atitude crítica, que ao fim os leve eventualmente a modificar estas instituições (e portanto a sociedade) em direção a uma maior justiça. Por exem-

\footnotetext{
${ }^{4} \mathrm{Na}$ realidade poder-se-ia conceber ainda um patriotismo constitucional que tenha como objeto uma constituição injusta (num certo sentido isto acontecia na antiga Atenas, ainda que não se tratasse dum patriotismo exclusivamente constitucional) ou instituições injustas (nos próprios Estados Unidos, até a metade do século vinte estavam em vigor inaceitáveis normas de segregação racial).
} 
plo, no caso de Habermas, um dos maiores representantes do patriotismo constitucional, a afeição pelas instituições democráticas da República Federal de Alemanha não o impede de assumir uma posição crítica perante elas, no momento em que não ajam segundo a justiça; ou não o impede de criticar certas normas jurídicas, embora estabelecidas à base dos procedimentos democráticos em vigor, no momento em que elas não respondam a critérios universais de justiça, como por exemplo no caso das restrições no direito a asilo deliberadas há alguns anos pelo parlamento alemão. O patriota constitucional não crê cegamente nas instituições; ao contrário, sopesa-as com olho crítico e dirigido para a justiça. Quem pensa que este patriotismo seja frio e incolor, equivoca-se, pois o amor à justiça, como o amor à liberdade, pode levar a grandes atitudes. $\mathrm{O}$ patriotismo constitucional é um sentimento, ainda que temperado pela razão; um sentimento no qual confluem amor à pátria como Heimat, ou seja à pátria entendida como o lugar das afeições privadas; lealdade às instituições do seu país; e amor à justiça.

Com respeito a isso, é preciso relevar como o patriotismo constitucional não deve ser confundido com uma abstrata inclinação para a justiça. Patriota constitucional não é aquele que entre todas as comunidades políticas existentes ama aquela cujas instituições sejam as mais justas, mas sim quem ama as instituições da sua própria comunidade na medida em que elas correspondam a um ideal de justiça. Este, por sua vez, pode ter realizações diferentes nas diversas comunidades. Um patriota constitucional estadunidense pode amar as instituições do seu país enquanto elas asseguram ao indivíduo uma grande quantidade de liberdades e de direitos individuais, embora não assegurem igualdade econômica e social, enquanto um patriota constitucional alemão pode orgulhar-se do fato que a República Federal de Alemanha seja um estado social capaz de salvar os seus cidadãos da pobreza e de oferecer serviços sociais de alto nível a todos. Em ambos casos o nosso patriota - pois ele é dotado daquela atitude crítica que podemos licitamente esperar de um patriota constitucional - pode dedicar-se a fazer ainda mais justas as instituições do seu país, em direção respetivamente duma maior liberdade individual e dum estado social mais forte. Por fim: também no patriotismo constitucional fica um resíduo não eliminável de particularismo. Este último, porém, não é ligado a elementos substanciais e ambíguos como a comunhão de idioma, território, história, cultura e religião, mas sim a uma realidade institucional, cujas raízes não são os mencionados critérios "nacionais", mas sim a simples existência de comunidades políticas singulares, cada uma das quais possui o seu próprio projeto de vida pública, a sua própria concepção da justiça e 
uma idéia acerca do melhor modo para realizar esta concepção. O patriota constitucional identifica-se - em medida variável, pois ele deve possuir a já mencionada atitude crítica - nestas concepções. Ele possui uma ligação com os compatriotas por eles serem seus concidadãos, e não por eles serem membros do mesmo âmbito cultural, lingüístico etc.

Gostaria de apontar para o fato de que este tipo de patriotismo, embora seja ainda ligado a uma realidade territorial, o estado, não ser conexo com outras realidades mais radicadas num determinado território, como as já mencionadas (idioma, cultura etc.). Quando o estado não seja mais definido em termos de nação, de entidade étnica ou cultural, mas somente como projeto comum dum grupo de indivíduos, os seus cidadãos podem assumir uma nova perspectiva com respeito à questão da identificação com a sua comunidade política. Ao conceber a sua comunidade política como comunidade aberta, capaz de integrar-se numa comunidade mais ampla, como por exemplo os estados europeus integraram-se na União Européia, o cidadão conquista a capacidade de conceber-se a si mesmo como membro de diversas comunidades e, portanto, de sentir-se ligado numa relação da responsabilidade ainda perante outros indivíduos alheios a sua comunidade originária. Este conceito da responsabilidade precisa duma explicação.

Ser cidadão significa tomar parte no processo democrático de decisão. Nos estados onde isto não é possível, não há cidadãos, mas súditos. Até a abstenção constitui uma forma de participação política, embora negativa: como renúncia, como aval silencioso ou como protesto. Portanto, as responsabilidades das decisões tomadas neste processo recaem sobre todos os cidadãos, considerados como co-autores das decisões mesmas. Existe portanto um patriotismo da responsabilidade, que assim faz com que cada cidadão sinta-se responsável perante os concidadãos pelo fato de influir na vida deles. Também neste caso, como no patriotismo constitucional, a ligação com os compatriotas não nasce de dúbias identidades nacionais baseadas em conceitos porosos como: história comum, idioma comum, cultura comum etc.; ela nasce duma identidade coletiva centrada na noção de comunidade política aberta, entendida como projeto comum. Por fim: este patriotismo da responsabilidade é estreitamente conexo ao patriotismo constitucional, pois também ele insiste na dimensão institucional da filiação a uma comunidade política. Como já disse: os verdadeiros compatriotas são os concidadãos, apesar dos já mencionados elementos substanciais comuns. 


\section{Patriotismo e globalização}

Qual é então a conexão entre patriotismo constitucional, patriotismo da responsabilidade e globalização?

Ao falar da comunidade política, apontei para o fato que o fazer parte dela, e portanto o papel de cidadão, não são ligados necessariamente ao ser membros duma nação, duma cultura ou duma etnia. Ao mesmo tempo, os limites duma comunidade política são mutáveis: seja em sentido físico dos limites geopolíticos, seja em sentido mais metafórico do número dos indivíduos membros daquela comunidade. Portanto, a alternativa a um estado mundial unitário, no qual tanto se fala hoje, não é necessariamente a persistência dos estados nacionais assim como os conhecemos. É pensável, talvez desejável, uma redefinição dos limites estatais de maneira que surjam unidades territoriais capazes de satisfazer mais amplamente as exigências dos cidadãos: exigências com respeito aos direitos individuais, à participação política, ao caráter democrático das decisões que podem influenciar na vida deles. Sobretudo: uma vez que a afeição pela sua comunidade política resulte na realidade afeição pelas instituições na medida em que elas realizam uma determinada concepção da justiça, fica mais fácil a identificação com uma comunidade política mais ampla que realize nas suas instituições a mesma concepção da justiça ou uma concepção análoga. Um exemplo concreto pode ser oferecido outra vez pela União Européia, que representa um fenômeno de integração institucional de diversas comunidades políticas. Um patriota constitucional holandês, por exemplo, poderá tornar-se sem problemas patriota constitucional europeu no momento em que as instituições européias comuns realizem aqueles princípios de justiça perseguidos pelas instituições nacionais holandesas. Obviamente não se trata dum processo simples nem breve. Há primeiramente obstáculos relativos às diversas concepções da justiça. Depois, a simpatia pelas particularidades institucionais dos estados. Em seguida, a dificuldade de criar nos indivíduos aquele sentimento comum necessário para dar vida a uma comunidade política, neste caso no nível europeu. Porém, já foi feito muito caminho nesta direção, e o trajeto percorrido prova que a coisa é possível, desmentindo assim quem assevere o contrário. Não é preciso portanto pensar imediatamente na criação dum estado mundial. A criação de organismos internacionais resultantes da integração institucional de estados preexistentes, segundo o modelo da União Européia ou segundo um modelo ainda mais democrático, constituiria já um grande passo adiante. Por que não pensar, por exemplo, que o Mercosul possa tornar-se um organismo assim? 
Ao lado do patriotismo constitucional, há depois o mencionado patriotismo da responsabilidade. A consciência da própria responsabilidade pode ser estendida aos membros duma comunidade mais ampla independentemente da filiação comum à mesma etnia, cultura, nação etc. A quem objete que um sentimento de simpatia ou de solidariedade não pode ser ampliado a quantidades tão vastas de indivíduos, recordo que isto acontece (ou deveria acontecer, ainda e sobretudo na ótica do patriotismo tradicional) já em países de um bilhão e trezentos milhões, de duzentos e oitenta milhões ou de "só" cento e setenta e quatro milhões de habitantes.

Uma vez que sejam emancipados do egoísmo nacional, os indivíduos devem compreender que são corresponsáveis por cada ação ou cada política que tenha efeito sobre indivíduos membros da comunidade política mais ampla criada pela integração da própria comunidade originária com outras comunidades. Ainda neste caso, ética individual e questões de justiça social se interlaçam.

Esta consciência da própria responsabilidade pelas ações e pelas políticas da sua comunidade política não pode, porém, ser limitada à comunidade mais ampla que resulta da integração internacional na forma da criação de macrorregiões. Uma das características mais relevantes da globalização consiste precisamente no fato de que decisões políticas ou econômicas tomadas ao nível local podem possuir influência no nível global. O exemplo mais evidente é o consumo desmedido de energia e a conseqüente poluição do meio-ambiente operados pelos Estados Unidos, mas poderíamos mencionar ainda o desflorestamento da Amazônia. Quem praticar ações deste tipo deve estar disposto a assumir a responsabilidade por elas.

Thomas Pogge fez uma proposta muito interessante: a cobrança de uma taxa sobre os recursos naturais. Quem utiliza recursos naturais não renováveis, como o petróleo, ou que só podem renovar-se em prazos longuíssimos, como a água doce ou as florestas, deveria pagar uma taxa proporcional ao consumo. Os proventos desta taxa deveriam depois ser repartidos entre os países mais pobres, segundo critérios ligados às necessidades deles e sob a condição de que os fundos sejam utilizados para combater definitiva e eficazmente a pobreza dos habitantes - e isso não necessariamente através dos mecanismos tradicionais do livre mercado característico do mundo ocidental: soluções alternativas são possíveis e são já utilizadas, embora não em larga escala. 
O que seduz nesta idéia, apesar das dificuldades concretas, é o fato de que Pogge, longe de propor um modelo de organização duma simples caridade mundial, propõe a criação dum verdadeiro estado social em escala global, financiado por uma taxa sobre o consumo que toque precisamente os países mais dissipadores, que são atualmente também os mais ricos. Um estado social global é justificado não somente por causas humanitárias ou por razões de ética individual (como no caso da caridade), mas é baseado num princípio fundamental de justiça, o princípio segundo o qual quem seja responsável por uma situação negativa deve remediá-la, naquilo que estiver em seu poder. Porém, enquanto os indivíduos ficarem prisioneiros da ótica do egoísmo nacional, tão comum nos países ricos, in primis nos Estados Unidos e na Europa (mas também no Brasil, quando tratar-se da questão amazônica); enquanto - eu dizia - este egoísmo nacional seja dominante, nunca poderia desenvolver-se aquela consciência de responsabilidade global necessária para a solução dos problemas causados pela globalização.

\section{Referências bibliográficas}

Barber, B. (1995). Jihad vs. McWorld. New York: Ballantine.

Cerutti, F. (1996). Identità e política. In: F. Cerutti (org.), Identità e política. Roma/Bari: Laterza.

Fioravanti, M. (1993). Stato e costituzione: materiali per una storia delle dottrine costituzionali. Torino: Giappichelli.

Frankenberg, G. (1997). Die Verfassung der Republik: Autorität und Solidarität in der Zivilgesellschaft. Frankfurt am Main: Suhrkamp.

Habermas, J. (1996). Die Einbeziehung des Anderen. Frankfurt am Main: Suhrkamp.

Höffe, O. (1999). Demokratie im Zeitalter der Globalisierung, München: Beck.

Kelman, H. C. (1987). The political psychology of the Israeli-Palestinian conflict: how can we overcome the barriers to a negotiated solution? Political Psychology, v. 8, n. 3, p. 347-363.

Kymlicka, W. (1995). Multicultural citizenship: a liberal theory of minority rights. Oxford: Oxford University Press.

Pinzani, A. (2002). Interesse und Identität: zur Grundlegung einer nicht-realistischen Theorie internationaler Verhandlungen am Beispiel des israelisch-palästinensichen Konflikts. In: Jean-Christophe Merle (org.), Normative Bedingungen für internationale Verhandlungen (em publicação).

Sternberger, R. (1990). Verfassungspatriotismus. Frankfurt am Main: Insel.

Young, I. M. (1998). Selbstbestimmung und globale Demokratie: zur Kritik des liberalen

Nationalismus. Deutsche Zeitschrift für Philosophie, v. 46, n. 3, p. 431-57. 